\title{
Prospects of Automation Agents in Agribusiness (Hop Industry) Decision Support Systems Related to Production, Marketing and Education
}

\author{
Martin Pavlovic ${ }^{1}$ and Fotis Koumboulis ${ }^{2}$ \\ 1International Hop Growers' Convention, \\ ${ }^{2}$ Halkis Institute of Technology, \\ ${ }^{1}$ Slovenia \\ ${ }^{2}$ Greece
}

\section{Introduction}

Difficulty for decision making in modern agribusiness has increased significantly, since it involves a large number of strongly interrelated factors that affect the satisfaction of the performance criteria describing product quality, production timing and cost. In addition, decision making has to take into account regulations and restrictions concerning the safety of the personnel, the environmental protection and the energy saving. Moreover, agriculture is becoming more commercialized, as farmers are competing with other farmers all over the world. To face these challenges modern agricultural practices must be adopted; however, they require appropriately educated and informed farmers (Abdon \& Raab, 2004). So, the question is how to provide the required knowledge and information to farmers, even to those without a high education level.

A powerful tool to circumvent these difficulties is the technological area of agroinformatics and concerns the use of Information Management and Decision Support Systems (IMDSS). They aim to monitoring all functions of an agricultural process and facilitating decision making by proposing scenarios towards satisfying specific performance criteria and restrictions. IMDSS may perform several operations: monitoring the agricultural process, action planning and proposal of scenarios, processing of measurement data to extract information regarding the production cost and the product quality, fault diagnosis and alarm management.

Decision Support Systems (DSS) have been extensively used in industrial applications to support the human-supervisor decisions regarding assurance of efficient and safe processes operation (Lambert et al., 1999; Sanchez et al., 1996). The degree of automation in decision making is the major factor of differentiation between DSS. The DSS characterized by the lower degree of automation simply facilitate decision making by offering information to the operator; in an upper stage DSS incorporate decision-making units that simply propose actions without the jurisdiction of activation. DSS classified in the highest degree of 
automation completely replace - in certain activities - the human operator. The development of Automation Units for industrial decision making, being implemented as software agents, which may be incorporated in an abundance of commercial Supervisory Control and Data Acquisition (SCADA) products, has been proposed (Koumboulis \& Tzamtzi, 2005). The proposed Automation Agents for Decision Support Systems (AADSS) may cover a wide range of industrial applications, providing decision support of the highest degree of automation.

IMDSS specifically oriented for agribusiness applications are met both in the international practice and literature (McCown, 2002; Parrott et al., 2003). Most of them are designed to serve specific sectors of agribusiness, like cotton management (McCown, 2002), vegetable processing industry (Berlo van, 1993), soybean management (Welch et al., 2002), wheat cultivar selection and fertilization (McCown, 2002), irrigation (Mira da Silva et al., 2001), etc. Moreover, in most cases the proposed DSS are designed to support only a limited range of the decisions to be taken by the farmer. For example, a DSS called PCYield is designed to answer the following two questions aiming to support decisions concerning soybean cultivar selection: What yield range might be expected? And, what happens if irrigation is withheld for a time and the weather is dry? (Welch et al., 2002). An interesting case is DSS supporting farm planning (Recio et al., 2003), which involves a significant range of farming decisions, like scheduling of field tasks, investment analysis, machinery selection and cost/benefit analysis.

Increasing the functionality of DSS with additional characteristics have been proposed, for the example the use of operational research and management's science tools in order to integrate weather forecasts in decision making (Recio et al., 2003). Of special interest is the development of DSS that incorporate tools from agribusiness logistics (Berlo van, 1993; Folinas et al., 2003; Biere, 2001).

Several approaches have been used for developing DSS in agribusiness, based either on operational research/management science, on heuristic search or other artificial intelligence techniques (Recio et al., 2003). Three of the most popular are linear programming approaches, dynamic programming approaches, as well as model-based simulation approaches; a fuzzy logic based approach has also been proposed (Thangavadivelu \& Colvin, 1997) for scheduling tillage operations. Despite the research efforts for the development of DSS for agribusiness, farmers seem to be reluctant to involve DSS in their work; thus, the range of application of DSS in agriculture remains significantly smaller than in industry. According to McCown (2002), the two variables long recognized as key to user acceptance is perceived usefulness and ease of use.

The present work proposes stepwise development of Automation Agents for Decision Support Systems (AADSS) for agribusiness - applied in hop industry. Following Koumboulis and Tzamtzi (2005) for industrial applications, the automation agents will be implemented as software units, which may be incorporated in several commercial SCADA products. The proposed agents aim to support decision making in a significant range of the agribusiness operation, extending from cultivation techniques to farm planning and commerce of products, by undertaking to execute actions, like monitoring the agricultural process, providing e-learning functionalities, fault diagnosis, e-commerce support, planning based on logistics and processing of weather information. Thus the farmer is strongly supported with regard to all decision making that concerns the actions to be performed for 
all stages of agribusiness, from production to commerce. Moreover, the AADSS will provide a very friendly and easy to use graphical user interface, exploiting the graphical user interface capabilities of commercial SCADA products.

\section{Automation agents to support agribusiness management}

The proposed Automation Agents will be based on modern techniques of sustainable agriculture, so as to face the restrictions and difficulties of agricultural environment, such as high complexity, presence of uncertain and time changing factors, like weather, and restriction of natural sources, like water.

The proposed Automation Agents are the Operator Agent and the Supervisory Agents. The Supervisory Agents are the E-learning Agent, the Monitoring Agent, the Fault Diagnosis Agent, the Weather Information Agent, the Ecommerce Agent and the Logistics Agent. Their functionality aims to supervise all aspects of hop industry, from production to commerce, and moreover to provide e-learning services to farmers' group. It is important to note that the knowledge data base used for the E-learning Agent is dynamically adapted with any new information derived from processing the data gathered from the process. The Operator Agent exploits information gathered from all the aforementioned Automation Agents in order to support the farmer's decision making by proposing possible scenarios to the farmer. The interconnection between the Operator and the Supervisory Agents is illustrated in Figure 1.

\section{Operator Agent}

The Operator Agent will be implemented according to the DAI-DEPUR architecture, an integrated and distributed artificial intelligence supervisory architecture, proposed by Sanchez et al. (1996) for a waste-water treatment plant. The DAI-DEPUR architecture has also been used for the implementation of an Operator Agent for industrial applications (Koumboulis \& Tzamtzi, 2005). Below we present in short the DAI-DEPUR architecture as described by Sanchez et al. (1996).

The DAI-DEPUR architecture comprises the data level, the distributed knowledge level, the reasoning level and the supervisory level.

The data level comprises the data collection system, that receives data from the process sensors, and the data base management system. The distributed knowledge level comprises distributed agents each of which processes validates and monitors the available information for a specific subsystem of the process, in order to describe the subsystem's behavior. Their conclusions are sent to the supervisory level in order to diagnose the whole plant state. The distributed knowledge level comprises simulation modules, as well as knowledge acquisition modules. The role of the knowledge acquisition modules is two-fold; first a conceptual clustering of data is performed, that leads to a representation of the process domain of operation in terms of classes, and then conjunctive classification rules are determined.

The reasoning level manages a Case Library that contains information about previously experienced situations, as well as solutions that have been followed in the past for each of these situations. Besides, the reasoning level may evaluate proposed solutions using simulation. The Case Library is dynamically enriched with information regarding the newly experienced situations. 
The supervisory level gathers information from the distributed knowledge and the reasoning level, to determine the current status of process operation and coordinate the rest of Automation Agents. In our case the supervisory level is responsible for all decisions undertaken by the Operator Agent, that is:

1. Alarm management

2. Exchange of information between the Automation Agents

3. Configuration of the supervisory agents

4. Derivation and proposal of optimal, or at least suboptimal scenarios of actions to be undertaken by the farmer, based on specific performance requirements.

Due to the complexity of the agricultural processes, in conjunction with the large number of factors to be taken into account, it is a usual case in agribusiness to deal with competitive goals that is criteria that cannot be simultaneously achieved. For example, the improvement of the product quality usually increases the production cost; then scenarios proposed to the farmer should be based on a compromise between competitive design goals, performed to achieve the optimal result, regarding the economic issues of the process, like production cost and product quality, as well as energy or natural resources saving, while satisfying constraints imposed by environmental protection rules. This compromise may be formulated as an optimization under constraints problem (Koumboulis \& Tzamtzi, 2005).

\section{Supervisory Agents}

Six Supervisory Agents are proposed based on the following approaches, selected to serve the needs of agribusiness:

1. E-Learning Agent

2. Monitoring Agent

3. Fault Diagnosis Agent

4. Weather Information Agent

5. E-commerce Agent

6. Logistics Agent

The E-Learning Agent aims to educate farmers with regard to required information and knowledge concerning the production techniques and the commerce of the specific product. The E-Learning Agent comprises a historic module implemented by a database, and a knowledge processing unit. The historic module contains required information background in order to make decisions concerning the agricultural process. The historic module stores measurements regarding the agricultural process and the weather, technical and scientific information concerning for example cultivation methods, plant diseases, special characteristics of each plant variety, effect of the weather on the plant, etc.; market information, like the available stock for each plant variety, current prices, current request from a national or a global market, etc., as well as legislation rules and restrictions. The knowledge processing unit is used in order to dynamically adapt the historic module based on the newly gathered information. The E-Learning Agent exploits also the information stored in the Case Library of the Operator Agent's reasoning level concerning previously experienced situations.

The Monitoring Agent aims to provide the farmer, as well as the other Agents, all the necessary information regarding the current status of the agricultural process. For this 
purpose, the Monitoring Agent exploits the data level of the Operator Agent that collects information from the agricultural process sensors, like measurements of humidity and temperature, height of the plant, etc. These data are processed in order to derive information about the current status of the agricultural process, as for example the plant growth. The information provided by the Monitoring Agent is also used by the distributed knowledge level of the Operator Agent.

The Fault Diagnosis Agent aims to a timely diagnosis of any fault that may occur in the agricultural process, like plant diseases, harm caused by insects, malfunctioning of the irrigation system, problems due to weather conditions, etc. Fault detection is achieved using the information provided by the Monitoring Agent and it is based on specific fault detection rules provided by the historic module of the E-Learning Agent. Whenever a specific situation deviates from the rules provided by the historic module of the E-Learning Agent, data are either processed by the knowledge process unit of the E-Learning Agent or they are sent to an expert, in order to derive new rules that will enrich the fault diagnosis capabilities of the Agent. The Fault Diagnosis Agent may also use the functionality of the distributed knowledge level of the Operator Agent.

The Weather Information Agent aims to support the decision making process regarding the issues that concern weather conditions. This Agent gathers information from meteorological services, combining it with measurements from the cultivation site. Based on this information it provides short term prediction of weather conditions. Moreover, the Weather Information Agent cooperates with the historic module of the E-Learning Agent in a two fold manner: first it exploits information from the historic module to support the weather prediction process; secondly, the information gathered by the Weather Information Agent is used to enrich the historic module.

The E-Commerce Agent aims to support the sales through internet of agricultural products and it can also support the farmer in buying row material through internet. The E-Commerce Agents comprises an intelligent unit to use the market information stored in the historic module, in order to decide whether each buying or selling action is profitable for the farmer.

The Logistics Agent aims to support the farmer concerning decisions on planning and controlling an efficient flow and storage of raw materials, intermediate and final products from point of origin to point of consumption, so as to achieve specific performance requirements, while simultaneously satisfying constraints (Berlo van, 1993; Folinas et al., 2003; Biere, 2001). The performance requirements concern the product cost and quality, the satisfaction of the market demand, the optimal exploitation of the processing equipment and cultivation area, etc. The restrictions concern the storage capacity, the maximum allowed time of storage, the available cultivation capacity and the processing capacity, etc. The planning provided by the Logistics Agent should take into account time changing and uncertain factors, like the weather conditions and the demand of the market. The Logistics Agent may consider the whole logistical chain incorporating agriculture, processing industry and market, as was proposed in (Berlo van, 1993); in this case, the DSS should communicate with corresponding information systems of the processing industry and market sectors, in order to derive the data required.

\section{Embedding automation agents in SCADA systems}

The implementation of Automation Agents should satisfy certain functional specifications, like interactive communication, real time processing and precision of calculations. To 
achieve these goals, the software development of the Automation Agents is based, following Koumboulis and Tzamtzi (2005), on international standards for open architecture, which will assure the embedment of the software in several commercial SCADA products. These systems are modern Information Systems with build-in capabilities of network communication that have widely been used in modern industry. The subsystems of a SCADA system are:

1. Bilateral communication with the process: data acquisition from sensors and command transmission though appropriate actuators,

2. (Graphical User Interface (GUI), through which the operator monitors and commands the process and

3. Automation Agents for Decision Support System.

The AADSS functions, provided by most of the commercial SCADA products, are: storage of info to historical modules, statistical data processing, formulation of reports, and alarm management. The Automation Agents presented in the previous sections will utilize the network communication, collection, registration, depiction and data process capabilities provided by modern SCADA. For example, the data level of the DAI-DEPUR architecture will be implemented by the data processing unit of the SCADA system, while the alarm management operation performed by the supervisory level of the DAI-DEPUR architecture will be supported by the alarm handling unit of the SCADA system. Besides communication of Automation Agents with the human-operator will take place via the graphical user interface of SCADA system. The embedment of the Automation Agents in SCADA systems

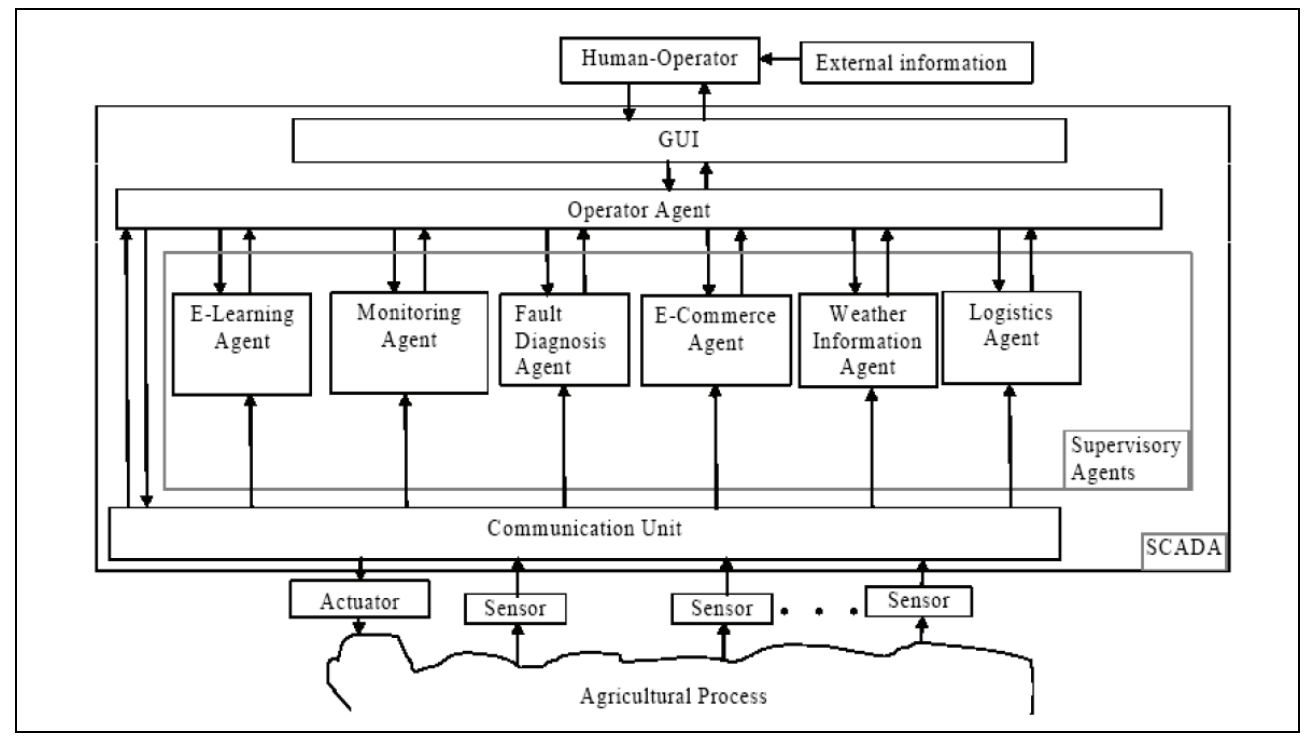

Fig. 1. Embedment of Supervisory and Automation Agents for Agribusiness in SCADA systems 
is achieved using the latest technology of modern software tools, supported by most of modern commercial SCADA programs, like the OPC (OLE for Process Control) that allows bilateral real time data transfer between different types of equipments, as well as established standards of object-oriented communication between heterogeneous applications of Windows operating systems, like COM and ActiveX. The embedment of Automation Agents into SCADA systems is presented (Figure 1).

\section{Model application in a hop industry}

An implementation of the proposed scheme is planed to take place within a framework of a research project for a case study in a hop industry that is related predominantly to a brewing industry. Beer brewing is an intricate process encompassing mixing and further elaboration of four essential raw materials, including barley malt, brewing water, hops and yeast. Particularly hops determine to a great extent typical beer quality such as bitter taste, hoppy flavour, and foam stability. Adding different hop varieties to the wort kettle produces the typical beer aromas.

The benefits and opportunities for a hop industry to establish its informative and useful information management system is mainly due to the following reasons:

1. Hops are a classic internationally agricultural traded commodity, one of the few internationally traded goods bought and sold on world markets without any major economic restrictions, that is on the real basis of supply and demand. Thus, to remain competitive in global hop industry hop producers must respond to the changing needs of the brewing community by providing quality raw material from appropriate hop varieties.

2. The demands on production techniques, varieties, quality and preparation of export producing hops is changing constantly (Pavlovic et al., 2003; Pavlovic \& Koumboulis, 2004). For the sake of international character of hops as well as stakeholders' initiatives,

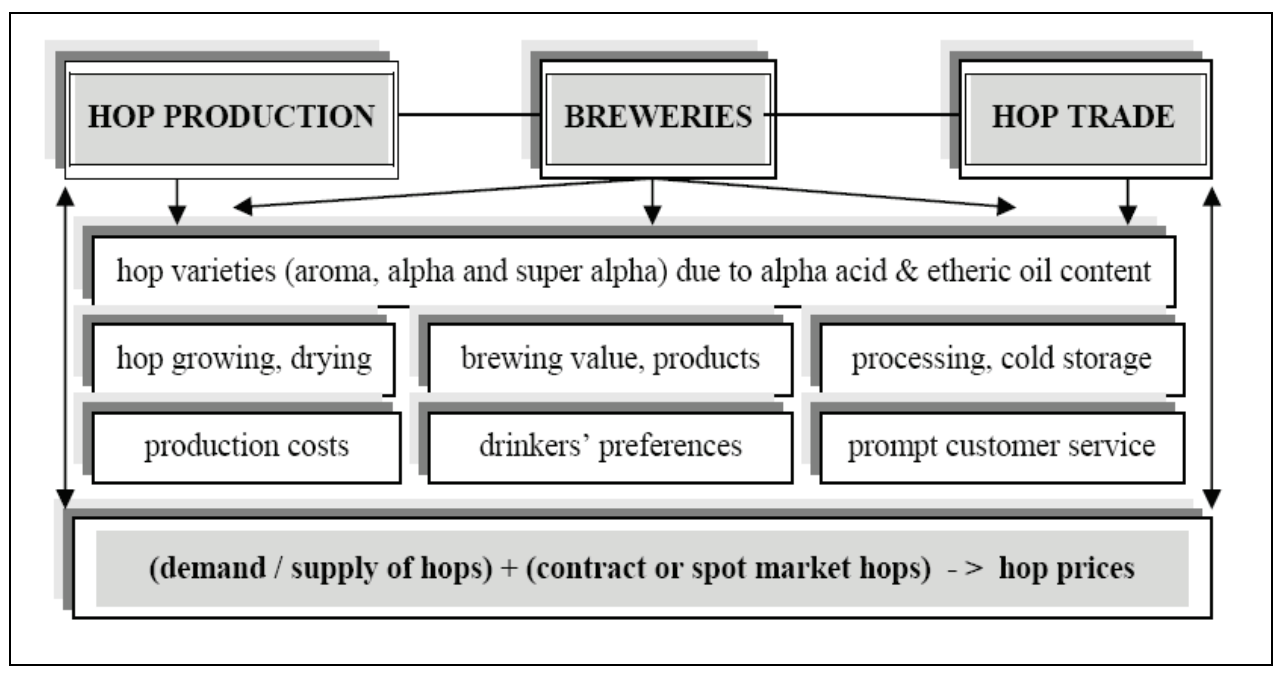

Fig. 2. Quality and business circle in a hop industry 
the International Hop Growers' Convention (IHGC) with 33 companies and organisations from 20 countries is supporting activities to improve the information management for a benefit of its members (Figure 2).

Furthermore, also benefits related to raw material quality management for the brewing industry are expected. The four largest breweries such as Anheuser-Busch InBev (Belgium/USA) with its share of world beer production of 22,2\%; SABMiller (UK) - $11.0 \%$; Heineken (NL) - 9.0\%; Carlsberg (DK) - 6.1\%; produced in 2007 around 50\% of the world beer quantity. However, there are also many small scale breweries that may benefit from the AADSS model information results.

Regardless the size of a brewing company, the product principles as well as the objectives regarding technology and purchasing are more or less the same: to use raw materials as economically as possible in the brewing process (Pavlovic \& Koumboulis, 2004).

\section{Conclusions}

The proposed Automation Agents are planed to be applied in a decision support system for a hop industry. However, they represent generalised tools applicable to some extent also to other agribusiness sectors. The proposed AADSS is particularly suited for large agricultural production units, since for small units the decision making process is significantly easier. Of special interest are farms with several plots of different crops, where the global farm resources have to be appropriately distributed among the plots, as well as farms simultaneously coordinated, as is the case of agricultural cooperatives.

The proposed Agents may contribute to farmers' education, to early correct fault diagnosis and incorporation of modern agricultural techniques, to process historical data taking into account several factors in order to support decision making, and to support the farmer in ecommerce activities. The incorporation of Automation Agents in DSS will contribute considerably in the decongestion of the responsibilities of the farmer. Thus farmers are assisted to focus on higher level operations like production planning and commerce. On the other hand, production costs are decreased, as the performance criteria can be achieved in a more precise manner and with less human effort. Finally, the environmental protection may benefit significantly since the proposed agents will contribute to a better exploitation of natural sources, as well as energy saving. The implementation of the Automation Agents is based on open architectures, so as to give the capability of integration in a crowd of commercial SCADA systems, fact that simplifies significantly the development and implementation procedure of the Automation Agents. What is more, the graphical user interface of SCADA systems provides a user friendly environment that will increase the farmers' acceptance.

\section{References}

Abdon, B. R. \& Raab, R. T. (2004). Knowledge sharing and distance learning for sustainable agriculture in the Asia Pacific Region: The role of Internet. New directions in a diverse planet. Proc. of the 4th Int. Crop Science Congress, Brisbane, Australia, Sept. 26. - 10. Oct. 2004.

http://www.cropscience.org.au/icsc2004/ 
Berlo van, J.M. (1993). A decision support tool for the vegetable processing industry; an integrative approach of market, industry and agriculture'. Agricultural Systems 23: 91-109.

Biere, A.W. (2001). Agribusiness logistics: An emerging field in agribusiness education'. In: IAMA World Food and Agribusiness Symposium. Sydney, Australia, 27. June, 2001.

http://www.ifama.org/conferences/2001Conference/Papers/Area\%20I/Biere_Ar lo.PDF

Folinas, D.; Vlachopoulou, M.; Manthou, V. \& Manos, B. (2003). A web-based integration of data and processes in the agribusiness supply chain. EFITA 2003 Conference. Debrecen, Hungary: 143-149.

Koumboulis, F. N. \& Tzamtzi, M. P. (2005). Automation Agents Embedded in Industrial Decision Support Systems. In: International Conference on Intelligent Agents, Web Technologies and Internet Commerce - IAWTIC'2005. Vienna, Austria. pp: 51-57.

Lambert, M.; B. Riera \& Martel, G. (1999). Application of functional analysis techniques to supervisory systems. Reliability Eng. \& System Safety 64: 209-224.

McCown, R. L. (2002). Changing systems for supporting farmers decisions: Problems, paradigms, and prospects. Agric. Systems 74: 179-220.

Mira da Silva, L.; Park, J. R.; Keatinge, J. D. H. \& Pinto, P. A. (2001). A decision support system to improve planning and management in large irrigation schemes. Agric. Water Manag. 51: 187-201.

Parrott, L.; Lacroix, R. \& Wade, K. M. (2003). Design considerations for the implementation of multi-agent systems in the dairy industry. Computers and Electronics in Agric. 38: 79-98.

Pavlovic, M.; Koumboulis, F. N.; Tzamtzi, M. P. \& Karras, D. A. (2003). Model of information management and data exchange on a global hop supply. Proc. of the 2nd Int. Symp. on Intelligent Information Technology in Agriculture. Beijing, China, pp. 20-23.

Pavlovic, M. \& Koumboulis, F. M. (2004). Methodology of an IHGC Market Supply Data Collation. (www.ihgc.org). Hop Bull. 11: 17-24.

Pavlovic, M.; Luo, X.; Kosir, I. J.; Virant, M. \& Gu, F. (2006). Expansion of the Chinese hop and brewing industry. Hop Bull. 13: 61-69.

Pavlovic, M.; Koumboulis, F. N.; Tzamtzi, M. P. \& Rozman, C. (2008). Role of automation agents in agribusiness decision support systems. Agrociencia 42: 913-923.

Recio, B.; Rubio, F. \& Criado, J. A. (2003). A decision support system for farm planning using AgriSupport II. Decision Support Systems 36: 189-203.

Sanchez, M.; Cortes, U.; Lafuente, J.; Roda, I. R. \& Poch, M. (1996). DAIDEPUR: An integrated and distributed architecture for waste-water treatments plants. Artificial Intelligence in Eng. 1: 275-285.

Thangavadivelu, S. \& Colvin, T. S. (1997). Fuzzy-Logic-Based decision support system for scheduling tillage operations. Eng. Applications of Artificial Intelligence 10: 463472 . 
Welch, S. M.; Jones, J. W.; Brennan, M. W.; Reeder G. \& Jacobson, B. M. (2002). PCYield: Model-based decision support for soybean production. Agric. Systems 74: 79-98. 


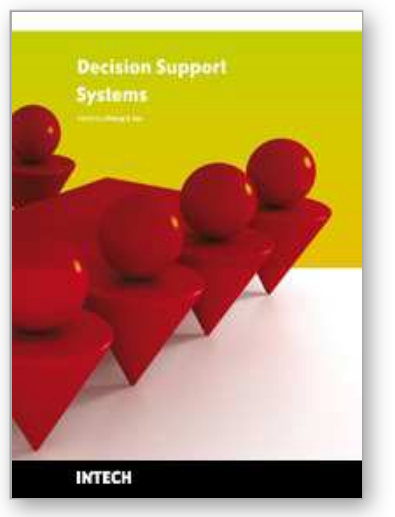

\author{
Decision Support Systems \\ Edited by Chiang S. Jao
}

ISBN 978-953-7619-64-0

Hard cover, 406 pages

Publisher InTech

Published online 01, January, 2010

Published in print edition January, 2010

Decision support systems (DSS) have evolved over the past four decades from theoretical concepts into real world computerized applications. DSS architecture contains three key components: knowledge base,

computerized model, and user interface. DSS simulate cognitive decision-making functions of humans based on artificial intelligence methodologies (including expert systems, data mining, machine learning, connectionism, logistical reasoning, etc.) in order to perform decision support functions. The applications of DSS cover many domains, ranging from aviation monitoring, transportation safety, clinical diagnosis, weather forecast, business management to internet search strategy. By combining knowledge bases with inference rules, DSS are able to provide suggestions to end users to improve decisions and outcomes. This book is written as a textbook so that it can be used in formal courses examining decision support systems. It may be used by both undergraduate and graduate students from diverse computer-related fields. It will also be of value to established professionals as a text for self-study or for reference.

\title{
How to reference
}

In order to correctly reference this scholarly work, feel free to copy and paste the following:

Martin Pavlovic and Fotis Koumboulis (2010). Prospects of Automation Agents in Agribusiness (Hop Industry) Decision Support Systems Related to Production, Marketing and Education, Decision Support Systems, Chiang S. Jao (Ed.), ISBN: 978-953-7619-64-0, InTech, Available from: http://www.intechopen.com/books/decisionsupport-systems/prospects-of-automation-agents-in-agribusiness-hop-industry-decision-support-systemsrelated-to-prod

\section{INTECH}

open science | open minds

\section{InTech Europe}

University Campus STeP Ri

Slavka Krautzeka 83/A

51000 Rijeka, Croatia

Phone: +385 (51) 770447

Fax: +385 (51) 686166

www.intechopen.com

\section{InTech China}

Unit 405, Office Block, Hotel Equatorial Shanghai

No.65, Yan An Road (West), Shanghai, 200040, China 中国上海市延安西路65号上海国际贵都大饭店办公楼 405 单元

Phone: +86-21-62489820

Fax: $+86-21-62489821$ 
(C) 2010 The Author(s). Licensee IntechOpen. This chapter is distributed under the terms of the Creative Commons Attribution-NonCommercialShareAlike-3.0 License, which permits use, distribution and reproduction for non-commercial purposes, provided the original is properly cited and derivative works building on this content are distributed under the same license. 